\title{
Microcontroller-based Bird Pest Repellent in Rice Plants
}

\section{Rancang Bangun Alat Pengusir Hama Burung Pada Tanaman Padi Berbasis Mikrokontroler}

\author{
Nonik Silvia Agustin $\left.^{1 *}\right)$, Koko Joni ${ }^{2}$, Diana Rahmawati ${ }^{3,}$ Adi Kurniawan Saputro ${ }^{4}$ \\ \{Corresponding Author: noniksilvia98@gmail.com ${ }^{1}$ \}
}

Program Studi Teknik Elektro, Fakultas Teknik, Universitas Trunojoyo Madura

\begin{abstract}
In the cultivation of rice, there is never a problem with the name pests. If not controlled, the pest attack will affect the productivity level of the plant. Pests that attack rice plants include leafhoppers and birds. Birds have a very large percentage rate in attacking rice plants, namely the bondol bird which is one of the grain-eating birds. This bird is a very troubling pest for rice farmers because it causes crop yields to drop dramatically. There are several ways to repel birds, usually farmers using the manual method by making a rice field and crackle which is then tied to a rope. When using this method, farmers have to wait for agricultural land for approximately one month. This is considered inefficient considering the farmer's job is not only to wait for the rice plant until harvesting. So that in this study, a tool that will be used to repel bird pests will be designed by using solar panels as a source of voltage with sound output using a frequency of $1.5-3 \mathrm{KHz}$.
\end{abstract}

Keywords - bondol birds; frequency; ic 555

\begin{abstract}
Abstrak. Dalam budidaya tanaman padi, tidak akan pernah lepas dari yang namanya hama. Jika tidak dikendalikan maka serangan hama akan mempengaruhi tingkat produktifitas dari tanaman tersebut. Hama penyerang tanaman padi antaranya wereng dan burung. Burung mempunyai tingkat persentase yang sangat besar dalam menyerang tanaman padi, yaitu burung bondol yang merupakan salah satu burung pemakan biji bijian. Burung ini menjadi hama yang sangat meresahkan bagi para petani karena menyebabkan hasil panen turun drastis. Terdapat beberapa cara untuk mengusir burung biasanya petani menggunakan cara manual dengan membuat orang sawah dan kresek yang kemudian diikatkan pada tali, ketika menggunakan cara ini petani harus menunggu lahan pertanian selama lebih dari satu bulan. Hal ini dianggap kurang efisien mengingat pekerjaan petani tidak hanya menunggu tanaman padi hingga menjelang panen. Sehingga pada penelitian ini akan dirancang sebuah alat yang difungsikan untuk mengusir hama burung dengan menggunakan panel surya sebagai sumber tegangan dengan ouput suara menggunakan frekuensi $1.5 \mathrm{KHz}-3 \mathrm{KHz}$.
\end{abstract}

Kata Kunci - burung bondol; frekuensi; ic 555

\section{Pendahuluan}

Indonesia merupakan salah satu negara tropis yang dapat ditanami hampir semua tanaman, terutama padi, karena padi merupakan salah satu sumber karbohidrat terbesar yang dapat memenuhi kebutuhan mayoritas penduduk di seluruh negara. Selain itu padi dapat ditanam 2-3 kali dalam setahun [1]. Bagi para petani, musuh terbesar mereka adalah hama, salah satu hama yang membuat hasil panen mereka turun adalah burung, karena burung akan memakan biji padi ketika biji padi berusia 70-110 hari [2]. Burung pemakan padi ini termasuk golongan burung pemakan biji bijian yang termasuk dalam jenis burung bondol (genus lonchura) atau biasanya dinamai burung pipit atau emprit oleh orang jawa [3]. Mereka berkeliaran di sekitar kita, membuat sarang sarang tajuk pepohonan, bertengger di kabel listrik, terbang membawa rerumputan kering, melintasi dan memakan bulir bulir padi. Macam macam burung yang sering berkeliaran dan merusak tanaman padi yaitu burung bondol jawa (L. leucogastroides), bondol peking (Lonchura punctulate) dan bondol haji (L. maja) [4].

Burung akan menyerang lahan padi pada jam 6 pagi sampai jam 6 sore atau menjelang magrib [5]. Ketika petani sudah menyambut masa musim panen populasi burung bondol yang besar ini akan membentuk kelompok kecil, mengitari area persawahan dan hinggap di pepohonan sekitar [6]. Gerakan burung ini sangat gesit sekali. Untuk menakut nakuti burung, selama ini petani hanya menggunakan cara manual yaitu dengan membuat orang orangan sawah atau memedi manuk dan juga tali yang kemudian di ikat dengan kaleng atau sesuatu yang berbunyi keras ketika digerakkan akan mengganggu pendengaran si burung serta biasanya para petani ini akan berteriak sekencang kencangnya supaya burung itu takut dan pergi [7]. Tapi cara ini dinilai kurang efektif karena akan menghambat pekerjaan lain dari petani, karena harus menunggu lahan padi dari munculnya burung sampai perginya burung.

Untuk lebih menghemat energi dan memanfaatkan kecanggihan teknologi yang sudah ada dan semakin berkembang maka dari itu saya ingin membuat alat pengusir hama burung otomatis menggunakan panel surya sebagai sumber tegangan dengan keluaran berupa suara bising agar mempermudah pekerjaan petani sekaligus dapat 
meningkatkan hasil panen para petani. Supaya para petani dapat melakukan pekerjaan lain dan tidak khawatir akan hasil panennya yang akan menurun. Hal ini lebih efektif daripada dilakukan dengan cara manual yang menguras tenaga dan membuang waktu. Alat yang akan dibuat menggunakan panel surya, mikrokontroler, speaker sebagai output untuk mengeluarkan suara dengan frekuensi untuk mengusir burung, dan komponen lain yang akan rancang menjadi satu.

\section{METODE}

Pada tahap perancangan sistem, akan dilakukan melalui 2 tahap, yang pertama adalah tahap perancangan perangkat keras atau hardware dan yang kedua adalah perancangan pada perangkat lunak atau software. Pada perangkat keras akan dilakukan pembuatan desain rangkaian hardware serta desain perancangan system tersebut.

\section{A. Blok dan skematik diagram}

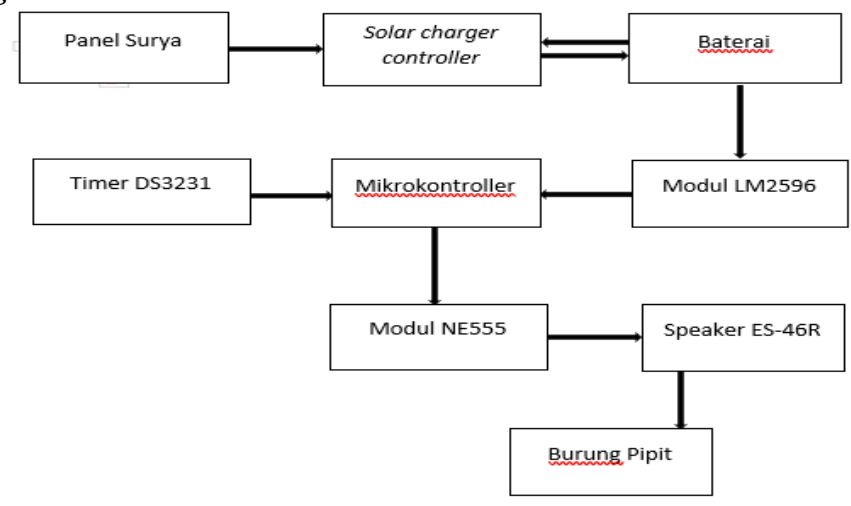

Gambar 1. Blok Diagram

Dari gambar 1. dapat dijabarkan bahwa panel surya merupakan sumber listrik untuk kelangsungan dari sebuah alat pengusir hama burung. Solar charge controller merupakan alat pengontrol input energi sinar matahari antara panel surya, baterai dan juga beban. Baterai adalah suatu komponen untuk menyimpan daya yang kemudian akan mengalirkan energi ke semua perangkat yang telah dikonversikan oleh solar charger controller. Modul LM2596 digunakan untuk menurunkan tegangan dari $12 \mathrm{~V}$ menjadi $5 \mathrm{~V}$, karena yang dibutuhkan oleh mikrokontroler adalah tegangan $5 \mathrm{~V}$, sedangkan tegangan $12 \mathrm{~V}$ merupakan tegangan dari aki/baterai. Mikrokontroller menggunakan Arduino nano atau ATMega 328 dan arduino IDE sebagai softwarenya. Mikrokontroler berfungsi sebagai pengendali dari keseluruhan berjalannya system ini. Relay digunakan untuk mengendalikan sirkuit tegangan tinggi dengan bantuan dari signal tegangan rendah, yangmana dalam system ini berfungsi sebagai saklar. Modul IC NE555 sebagai delay timer yang berupa chip yang kemudian digunakan sebagai pembangkit sinyal frekuensi yang dikeluarkan oleh suara speaker. Modul ini yang nantinya akan dapat diatur frekuensi berapa yang akan digunakan untuk ujicoba. Speaker ES-46R berfungsi sebagai pengeras suara yang mengusik burung.

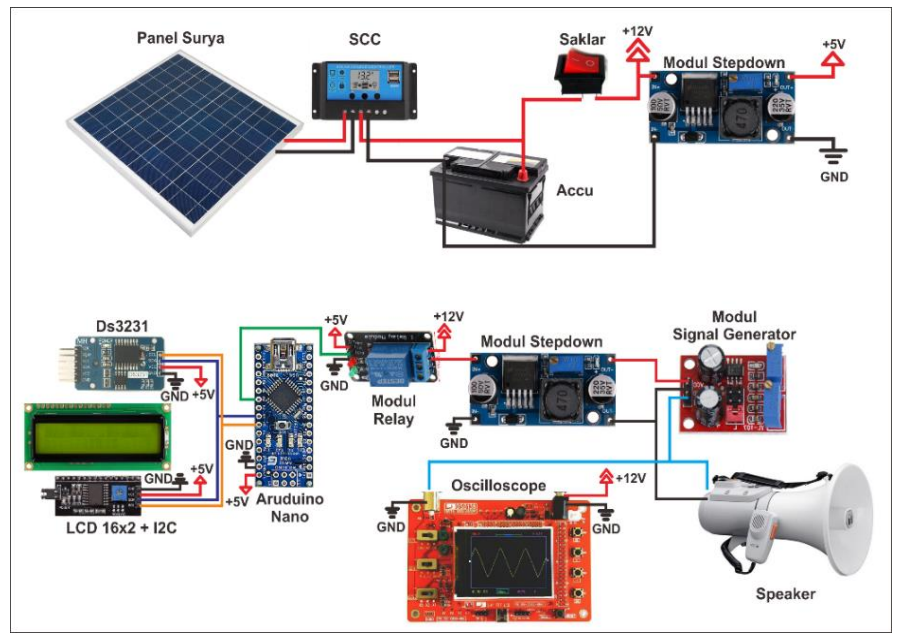

Gambar 2. Skematik Diagram 
Dari gambar 2. dijelaskan bahwa mikrokontroller sebagai pengontrol atau pengatur dari perangkat pengusir burung. Cahaya matahari menjadi sumber utama yang akan diubah menjadi energi listrik oleh panel surya, cahaya akan ditangkap oleh panel surya kemudian akan dikonversikan oleh solar charger controller dan akan disimpan pada baterai. Dalam memilih panel surya harus disesuaikan dengan kebutuhan dengan perhitungan dan efisiensi setiap Wp nya. Dari baterai akan disambungkan ke stepdown agar tegangan baterai dapat diturunkan dari $12 \mathrm{~V}$ menjadi $5 \mathrm{~V}$, kemudian baru akan di sambung dengan mikrokontroller yang berfungsi sebagai otak dari berjalannya keseluruhan system. Untuk mengatur alat supaya dapat bekerja setiap 30 detik sekali menggunakan modul DS3231. LCD digunakan untuk interface supaya dapat mengetahui alat hidup atau mati. I2C (Inter Integrated Circuit) merupakan komunikasi serial dua arah yang dapat mengirim dan menerima data, selain into I2C mempunyai kelebihan yaitu dapat diparalel dengan banyak perangkat yang menggunakan 2 kabel yang digunakanm yaitu SDA (Serial Data) dan SCL (Serial Clock) dengan begini pengkabelan yang digunakan lebih sedikit. Untuk mengetahui frekuensi yang dihasilkan oleh speaker dapat dilihat menggunakan osiloskop, di dalam osiloskop dapat diketahui beberapa hal, antara lain frekuensi, cycle, pulse width, duty cycle, $v$ max, v min, v rata rata dan juga bentuk gelombang. Modul IC NE555 berguna sebagai pembangkit sinyal suara dan juga untuk mengatur frekuensi yang dibutuhkan, modul ini menyediakan frekuensi antara $1 \mathrm{~Hz}-200 \mathrm{KHz}$.

\section{B. Desain alat}

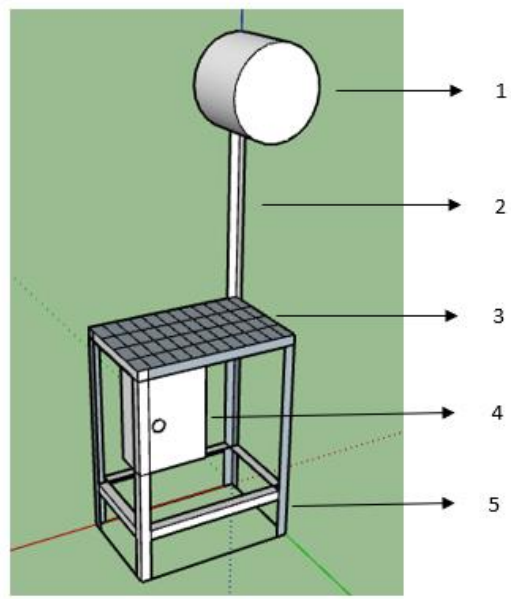

Gambar 3. Desain Alat

Keterangan :

1. Speaker

Speaker yang digunakan dalam sistem ini adalah speaker ES-46R yang mempunyai kapasitas tegangan maksimal 12 Volt. Di dalam speaker ada modul IC NE555 yang digunakan untuk mengatur frekeunsi sesuai yang dibutuhkan, frekuensi yang dibutuhkan dapat di atur pada modul IC NE555 ini yang diputar secara manual.

2. Tiang penyangga besi

Digunakan untuk menyangga speaker berukuran 1,5 meter tinggi speaker dapat disesuaikan dengan kebutuhan.

3. Panel surya

Panel surya yang digunakan adalah panel surya $20 \mathrm{Wp}$, digunakan untuk mengkonversi energi matahari menjadi energi listrik. Kapasitas tegangan maksimal dari panel surya adalah 17,5 Volt dan arus maksimal adalah 1,14 Ampere dan daya maksimal yang dihasilkan adalah 20Wp per jam [8].

4. Box panel

Digunakan untuk tempat penyimpanan dari seluruh sistem elektronika dan mikrokontroler supaya lebih aman. Di dalam box panel ada beberapa komponen utama antara lain adalah :

- Baterai yang digunakan merupakan baterai merk SMT yang mempunyai kapasitas tegangan keluaran 12 Volt, mempunyai kapasitas arus 7,5 Ah.

- Solar charge controller yang digunakan adalah SCC yang mempunyai kapasitas tegangan 12 Volt dan kapasitas arus sebesar $20 \mathrm{~A}$.

- Stepdown yang digunakan adalah tipe LM2596.

- Mikrokontroller yang digunakan merupakan arduino nano atau AT-Mega 328 memiliki 32 Kbyte On Chip In - System Reprogrammable Flash Memory yang digunakan untuk menyimpan program dan menyimpan vektor interupsi [9].

- RTC yang digunakan adalah real time clock tipe DS3231. 
- Lcd digunakan untuk interface antara sistem dengan pengguna agar dapat mengetahui kondisi speaker. LCD yang digunakan merupakan LCD 2x16.

- I2C berfungsi sebagai serial komunikasi dua arah yang dapat menerima maupun mengirim data juga untuk meminimalisir pin yang dipakai

- Osiloskop berfungsi untuk mengetahui bentuk gelombang, frekuensi dan duty cycle yang dikeluarkan oleh speaker.

5. Tiang penyangga besi utama

Tiang penyangga besi utama terbuat dari besi L yang disambung dengan paku ripet digunakan untuk menopang dari keseluruhan sistem

\section{Hasil dan Pembahasan}

\section{A. Pengujian IC 555}

Berdasarkan spesifikasi dari modul ic 555 mempunyai tegangan masukan 4,5 Volt sampai 15 Volt, maksimum output adalah 200mA [10]. Modul ini digunakan untuk pembangkit sinyal gelombang frekuensi yang mana frekuensinya dapat di atur mulai dari $1 \mathrm{kHz}$ yang menggunakan jumper dan timer.

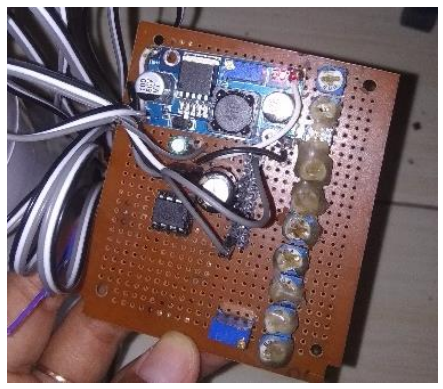

Gambar 4. Rangkaian IC 555

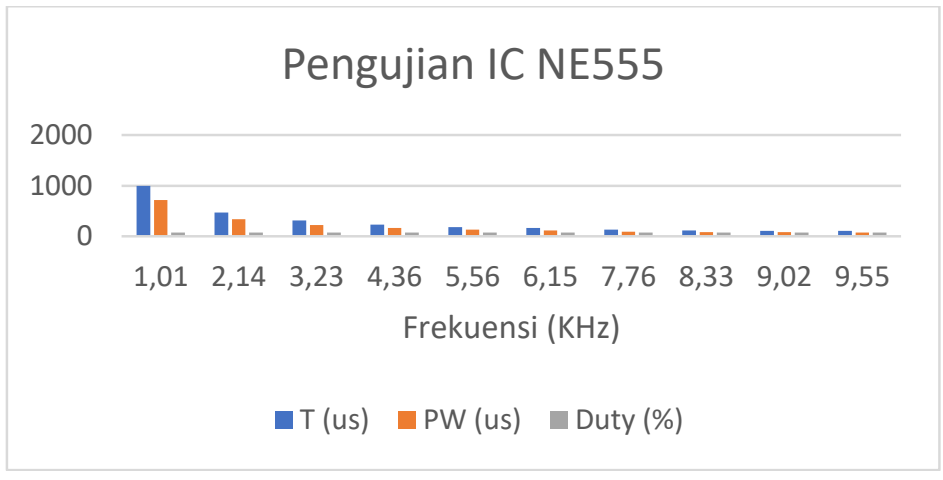

Gambar 5. Pengujian IC 555

Dari gambar 5. dilakukan pengujian frekuensi $1 \mathrm{KHz}$ sampai 9,55 KHz. Data yang ada berupa frekuensi, periode dalam satuan mikro sekon (us), dan pulse width (us), serta duty (\%). Frekuensi merupakan getaran yang dihasilkan dalam satu sekon, periode merupakan banyaknya waktu yang diperlukan untuk melakukan suatu getaran tersebut, pulse width modulation (PWM) atau sering disebut dengan modulasi lebar pulsa adalah suatu modulasi yang mengubah lebar pulsa dengan nilai frekuensi dan amplitude, sedangkan duty cycle merupakan siklus kerja saat sinyal PWM dalam kondisi hidup. Dapat diketahui dari tabel 4.4 bahwasanya saat frekuensi $1.01 \mathrm{KHz}$ memiliki periode sebesar 995 us, nilai PW adalah 720 us, dan duty cycle yang dihasilkan sebesar 72\%.

\section{B. Pengujian burung dengan frekuensi}

Pengujian frekuensi yang dilakukan bertujuan untuk dapat mengetahui tingkatan frekuensi yang dapat mengusir burung. Frekuensi dari modul ic 555 yang dikeluarkan melalui speaker berupa suara. Uji coba dilakukan langsung di lahan persawahan padi yang sedang masak atau menguning berisi. Ada 7 frekuensi yang digunakan untuk percobaan yang disesuaikan berdasarkan penelitian sebelumnya. Untuk lebih jelasnya adalah sebagai berikut. 
Tabel 1. Pengujian Burung dengan Frekuensi

\begin{tabular}{ccccc} 
& Frekuensi & \multicolumn{3}{c}{ Keadaan Burung } \\
\cline { 3 - 5 } No. & $(\mathrm{KHz})$ & $\begin{array}{c}\text { Tidak } \\
\text { Terganggu }\end{array}$ & $\begin{array}{c}\text { Sedikit } \\
\text { Terganggu }\end{array}$ & $\begin{array}{c}\text { Terganggu } \\
\text { /Pergi }\end{array}$ \\
\hline 1 & 1.01 & $\checkmark$ & \\
\hline 2 & 1.48 & & $\checkmark$ \\
\hline 3 & 1.88 & & $\checkmark$ & $\checkmark$ \\
\hline 4 & 2.6 & & \\
\hline 5 & 3.2 & &
\end{tabular}

Dari hasil pengujian di atas dapat di analisa bahwa frekuensi yang dapat mengusir burung adalah pada frekuensi $1.01 \mathrm{KHz}$ sampai $3.2 \mathrm{KHz}$, frekuensi lebih dari itu tidak memberikan reaksi terhadap burung. Untuk frekuensi 1.01 $\mathrm{KHz}$ suara yang dikeluarkan oleh speaker dominan keras tetapi tidak terlalu nyaring/bising, itu yang mempengaruhi burung yang terusik hanya sedikit. Pada frekuensi $1.48 \mathrm{KHz}$ sampai $2.6 \mathrm{KHz}$ frekuensi yang dihasilkan berupa suara dari speaker terdengar sangat nyaring dan keras, sehingga mengganggu pendengaran burung pipit itu yang menyebabkan dapat mengusir burung. Pada frekuensi $3.2 \mathrm{KHz}$ suara dari speaker yang dihasilkan semakin kecil, ketika ada burung yang memakan padi tidak terlalu dapat mengusirnya. Frekuensi $4.3 \mathrm{KHz}$ sampai dengan frekuensi 5 suara yang dihasilkan kecil sekali, pada saat pengujian tidak memberikan reaksi terhadap burung bahkan burung tidak pergi dan tetap makan. Dari tabel 2.1 dijelaskan bahwa frekuensi yang dapat di dengar oleh burung terletak pada rentang frekuensi $250 \mathrm{~Hz}$ sampai $21.000 \mathrm{~Hz}$. Sedangkan speaker diperuntukkan untuk pendengaran manusia yang berkisar pada frekuensi $20 \mathrm{~Hz}-20.000 \mathrm{~Hz}$. Sehingga yang dapat didengar pada speaker adalah frekuensi 250 $\mathrm{Hz}-10.000 \mathrm{~Hz}$, selebihnya suara yang dihasilkan speaker tidak terdengar. Batas maximal jangkauan speaker adalah 6 meter di depan speaker, jika burung berada diluar jangkauan maka burung akan tetap makan dan tidak terusik sama sekali.

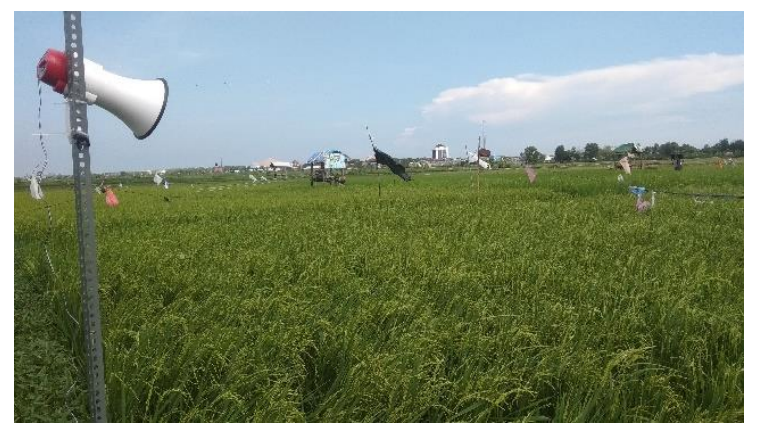

Gambar 6. Pengambilan Data di Lahan Persawahan

\section{Pengujian panel surya}

Pengujian panel surya yang dilakukan adalah untuk mengetahui kinerja dan mengetahui kemampuan dan kondisi panel surya. Data diperoleh dari logger yang telah dipasang pada alat pengusir hama burung ini. Data diambil mulai dari pukul 07.00 sampai 16.30 .

Pengujian panel surya dengan frekuensi $1.48 \mathrm{KHz}$

Pengujian ini dilakukan untuk dapat mengetahui daya panel yang dihasilkan dan daya beban yang dibutuhkan saat frekuensi berada pada nilai $1.48 \mathrm{KHz}$. 


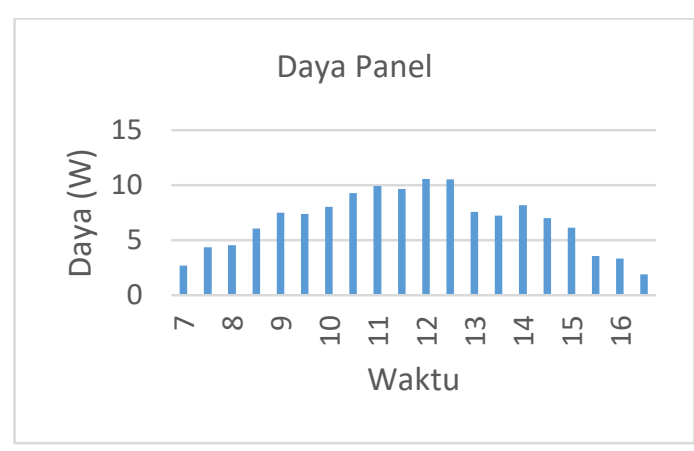

Gambar 7. Daya Panel saat Frekuensi $1.48 \mathrm{KHz}$

Dari gambar 7. dapat diketahui bahwa daya panel atau daya pengisian yang diperoleh total sebesar 135,61 W. Daya yang paling rendah pada saat pukul 16.30 dengan nilai 1.89 W. Sedangkan daya yang diperoleh dengan nilai tertinggi adalah pada saat pukul 12.00 sebesar $10,55 \mathrm{~W}$.

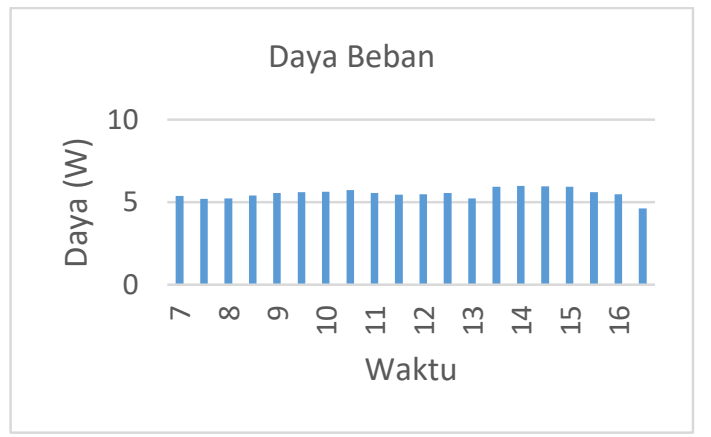

Gambar 8. Daya Beban saat Frekuensi $1.48 \mathrm{KHz}$

Dari gambar 8. dapat diketahui bahwa total daya beban atau daya keluar yang dibutuhkan adalah sebesar 110,62 W. Daya yang paling rendah pada saat pukul 16.30 dengan nilai $4.62 \mathrm{~W}$. Sedangkan daya yang diperoleh dengan nilai tertinggi adalah pada saat pukul 14.00 sebesar $6 \mathrm{~W}$.

Pengujian panel surya dengan frekuensi $1.88 \mathrm{KHz}$

Pengujian ini dilakukan untuk dapat mengetahui daya panel yang dihasilkan dan daya beban yang dibutuhkan saat frekuensi berada pada nilai $1.88 \mathrm{KHz}$.

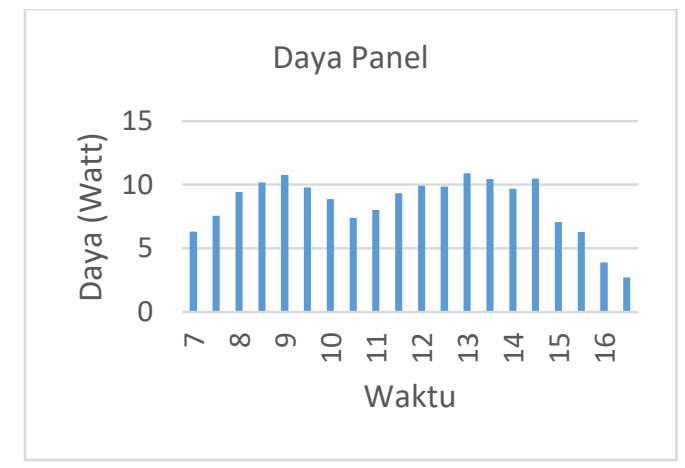

Gambar 9. Daya Panel saat Frekuensi $1.88 \mathrm{KHz}$

Dari gambar 9. dapat diketahui bahwa daya panel atau daya pengisian yang diperoleh total sebesar 168,88 W. Daya yang paling rendah pada saat pukul 16.30 dengan nilai $2,73 \mathrm{~W}$. sedangkan daya yang diperoleh dengan nilai tertinggi adalah pada saat pukul 13.00 sebesar $10,89 \mathrm{~W}$. 


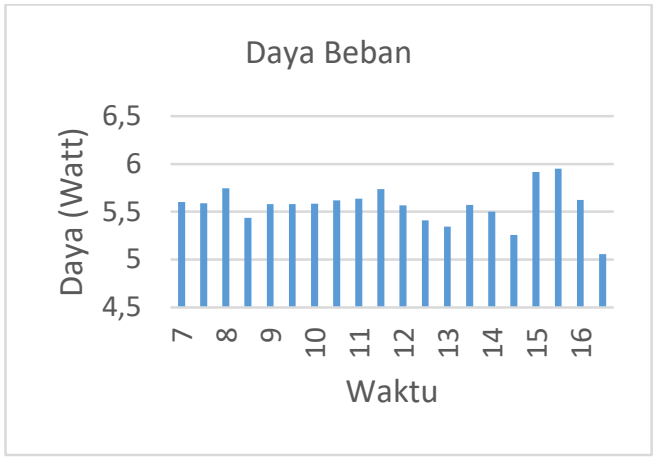

Gambar 10. Daya Beban saat Frekuensi $1.88 \mathrm{KHz}$

Dari gambar 10. dapat diketahui bahwa total daya beban atau daya keluar yang dibutuhkan adalah sebesar 111,30 W. Daya yang paling rendah pada saat pukul 16.30 dengan nilai 5,06 W. sedangkan daya yang diperoleh dengan nilai tertinggi adalah pada saat pukul 15.30 sebesar 5,94 W.

Pengujian panel surya dengan frekuensi $2.6 \mathrm{KHz}$

Pengujian ini dilakukan untuk dapat mengetahui daya panel yang dihasilkan dan daya beban yang dibutuhkan saat frekuensi berada pada nilai $2.6 \mathrm{KHz}$.

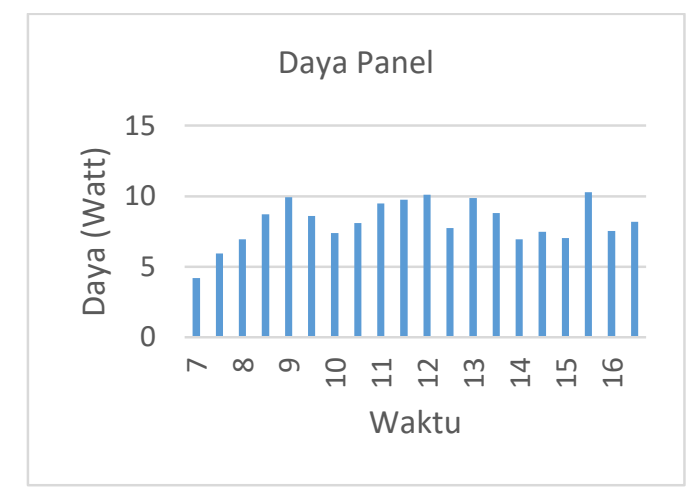

Gambar 11. Daya Panel saat Frekuensi 2.6KHz

Dari gambar 11. dapat diketahui bahwa daya panel atau daya pengisian yang diperoleh total sebesar $163.00 \mathrm{~W}$. Daya yang paling rendah pada saat pukul 07.00 dengan nilai 4,2 W. sedangkan daya yang diperoleh dengan nilai tertinggi adalah pada saat pukul 15.30 sebesar 10,26 W.

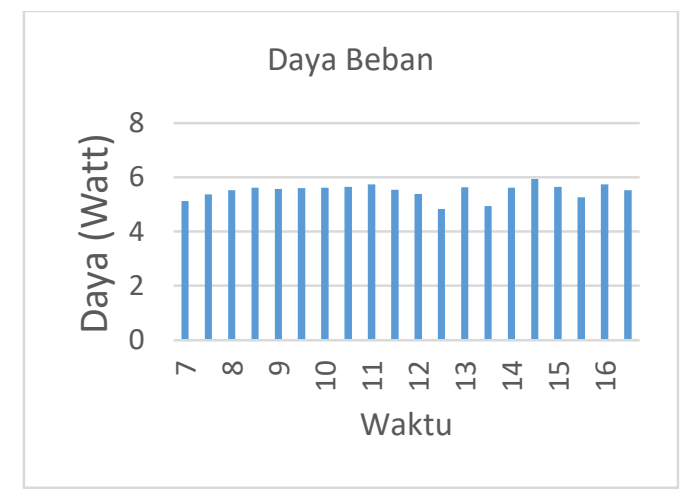

Gambar 12. Daya Beban saat Frekuensi 2.6KHz

Dari gambar 12. dapat diketahui bahwa total daya beban atau daya keluar yang dibutuhkan adalah sebesar $109.83 \mathrm{~W}$. Daya yang paling rendah pada saat pukul 12.30 dengan nilai $4.82 \mathrm{~W}$. sedangkan daya yang diperoleh dengan nilai tertinggi adalah pada saat pukul 14.30 sebesar 5,92 W. 


\section{KESIMPULAN}

Perancangan alat pengusir hama burung yang menggunakan ic 555 sebagai pembangkit gelombang frekuensi ini dikeluarkan melalui speaker. Jarak yang dapat dijangkau oleh speaker ES-46R hanya sejauh 6 meter di depannya, maka jarak yang lebih dari itu tidak akan memberikan reaksi apapun terhadap burung. Dari penelitian frekuensi yang lebih efektif digunakan untuk mengusir burung terletak pada frekuensi $1.48 \mathrm{KHz}-2.6 \mathrm{KHz}$, karena pada frekuensi ini dihasilkan suara yang nyaring dan keras. Daya dari panel surya masih dapat mencukupi daya yang dibutuhkan oleh beban dari alat pengusir burung ini, yang mana pada frekuensi $1.48 \mathrm{KHz}$ diperoleh daya panel sebesar $135,61 \mathrm{~W}$ dan daya beban sebesar 110,62 W. Sedangkan pada frekuensi $1.88 \mathrm{KHz}$ diperoleh daya panel sebesar 168,88 W dan daya beban sebesar 111,30 W. Pada frekuensi $2.6 \mathrm{KHz}$ diperoleh daya panel sebesar 163,00 W dan daya beban sebesar $109,83 \mathrm{~W}$.

\section{UCAPAN TERIMA KASIH}

Alhamdulillah, segala puji syukur saya persembahkan bagi Allah SWT yang telah melimpahkan berkat rahmat dan hidayah-Nya. Sehingga dalam penelitian yang berjudul "Rancang Bangun Alat Pengusir Hama Burung pada Tanaman Padi Berbasis Mikrokontroler" ini dapat berjalan dan terselesaikan dengan lancar dan baik. Terimakasih saya ucapkan kepada seluruh bapak dan ibu dosen S1 jurusan Teknik Elektro, prodi Teknik Elektro, fakutas Teknik, Universitas Trunojoyo Madura yang telah memberi illmu untuk mengajari dan selalu membimbing saya, serta semua pihak yang terlibat hingga selesainya penelitian ini.

\section{REFERENSI}

[1] Petaniindomodern, "Pengertian Tanaman Padi," 2016.

[2] Syahminan, "Prototype Pengusir Burung Pada Tanaman Padi Berbasis Mikrokontroler Arduino," vol. 9, no. 2, pp. 26-34, 2017.

[3] E. Roslinawati, W. Prihatini, and T. Haryoko, "Variasi Ciri Morfometrik Burung Bondol (Genus Lonchura) Di Indonesia," FMIPA Univ. Pakuan, no. 1, pp. 132-152, 2016.

[4] Sumariadi, Wildian, and M. Yusfi, "Aplikasi Mikrokontroler AT89S52 Sebagai Pengontrol Sistem Pengusir Burung Pemakan Padi Dengan Bunyi Sirine,” Fis. Unand, vol. 2, no. 1, pp. 64-71, 2013.

[5] A. A. Nugroho, "Prototipe Sistem Pengusir Hama Burung Berbasis Computer Vision," 2018.

[6] Burung Indonesia, "Bondol Jawa Pengintai Bulir Biji Padi," Bondol Jawa Pengintai Bulir Biji Padi, 2018. [Online]. Available: https://www.burung.org/2018/05/08/bondol-jawa-pengintai-bulir-biji-padi/. [Accessed: 16-Sep-2019].

[7] I. Buyung and A. W. Soejono, "Area Persawahan Dengan Menggunakan Gelombang Ultrasonik Berbasis Mikrokontroler Atmega168,” Univ. Respati Yogyakarta, vol. VII, no. 21, pp. 121-134, 2017.

[8] B. Ramadhani, "Instalasi Pembangkit Listrik Tenaga Surya Dos \& Don ’ ts," p. 277, 2018.

[9] A. Kadir, Pemrograman Arduino dan Processing. Jakarta: PT. Elex Media Komputindo, 2017.

[10] Nyebarilmu, "Pengertian Modul IC NE555," 2017. [Online]. Available: https://www.nyebarilmu.com/category/elektronika/. 